\title{
Merton in het laboratorium: netwerken of gunstenuitruil?
}

\section{Rene van der Eijk en Wilfred Dolfsma}

SAMENVATTING Dit artikel analyseert de bijdrage aan innovativiteit van onderzoekers in de context van een onderzoekslaboratorium door twee theoretische perspectieven met elkaar te combineren. Enerzijds is wel gesteld dat de structuur van relaties en de positie die iemand daarbinnen inneemt, bepalend zijn voor de mate waarin een onderzoeker innovatief is. Anderzijds kan de aard van de relaties die iemand onderhoudt, in termen van het wederzijds verlenen van gunsten (giften), uitmaken hoe sterk hij bijdraagt aan innovativiteit. In deze bijdrage worden deze beide perspectieven voor het eerst gecombineerd in een kwantitatief onderzoek, zodat een vergelijking mogelijk wordt. We laten zien dat de structuur van relaties belangrijker is dan de aard van relaties.

RELEVANTIE VOOR DE PRAKTIJK Te weten wat bijdraagt aan verhoogde innovativiteit van medewerkers (in een R\&D-laboratorium) en daarnaast te weten welke mogelijke vooroordelen de inschatting door een manager van de innovatieve bijdrage van medewerkers bepalen, is van groot belang. Deze bijdrage geeft op deze punten belangrijke inzichten voor managers. al., 2001), terwijl anderzijds kwalitatief onderzoek wijst op de rol van vertrouwen en sociaal kapitaal. Deze studie beoogt de beide onderzoeksrichtingen te combineren. Hierbij richten we ons op de uitwisseling van kennis binnen een laboratorium, anders dan bijvoorbeeld Bouty (2000), Cross en Cummings (2004) en Lam (2005), die ook uitwisseling van kennis met externen onderzochten. De vraag die we stellen, is vergelijkbaar aan de vraag die Merton (1968) ook al stelde in het licht van fundamenteel academisch onderzoek. Merton gaf aan dat de positie die een wetenschapper inneemt èn de aard van de relaties die hij heeft, kunnen verklaren hoe de wetenschappelijke bijdrage die hij levert zowel in objectieve als in subjectieve zin wordt geschat. Merton refereert aan het Matteüseffect als hij stelt dat wetenschappers die prominenter in een netwerk van relaties staan ook hoger aangeschreven worden en in een zichzelf versterkend proces daar ook meer de voordelen van genieten. Anders dan Merton maken wij een systematisch onderscheid tussen het structurele en het inhoudelijke aspect van relaties.

Het artikel heeft een klassieke opbouw. Allereerst bespreken we in paragraaf 2 de relevante literatuur, toewerkend naar een drietal hypothesen. Vervolgens beschrijven we de wijze van dataverzameling, de gebruikte maatstaven en de analysemethode in paragraaf 3. Paragraaf 4 bespreekt de gevonden resultaten, waarna conclusies volgen in paragraaf 5 .

\section{Het Matteïs-effect: structuur en inhoud van relaties}

Samenwerking tussen wetenschappers groeit in belang als gevolg van de cumulatieve aard van kennisontwikkeling en verdergaande specialisering van kennisontwikkeling (Ensign, 2009; March en Simon, 1958; Wuchty et al., 2007). Samenwerking kan direct zijn en de vorm krijgen van een gezamenlijk onderzoeksproject of meer indirect in de zin van 'standing on the shoulders of others'. Merton (1968, p. 57) geeft aan dat bij samenwerking in de 
praktijk 'eminent scientists get disproportionately great credit for their contributions to science while relatively unknown scientists tend to get disproportionately little credit for comparable contributions'. De percepties van iemands innovatieve bijdrage kan afwijken van de objectieve bijdrage. Merton wijst impliciet op twee aspecten van relaties die hierbij een rol spelen: de structuur van relaties zoals die vooral blijkt uit de mate waarin iemand centraal in het netwerk staat enerzijds, en de inhoud of aard van de relaties anderzijds. Om het laatste punt te maken, refereert Merton duidelijk aan de antropologische literatuur over giften(gunsten)uitwisseling waarin dominante personen onevenredig veel gunsten krijgen veel meer dan anderen dat krijgen en veel meer dan zij zelf geven.

Centraliteit. Onderzoekers die centraal in een netwerk van onderling verbonden onderzoekers staan, hebben hun positie verworven op grond van de kwaliteit van het onderzoek dat zij in het verleden hebben uitgevoerd in vergelijking met dat van hun evenknieën op dat moment (Sparrowe et al., 2001). Anderzijds ontvangen mensen die centraal staan meer informatie en inzichten van meerdere mensen dan personen die meer perifeer staan (Brass, 1984). Als gevolg daarvan zijn zij zelf veelal innovatiever dan anderen (Burt, 2004; Ibarra, 1993; Sparrowe et al., 2001), en kunnen dat voordeel ook beter uitbaten (Burt, 1992). Centraal gepositioneerde academici, zo stelt Merton (1968, p. 61), ontwikkelen metavaardigheden op grond waarvan zij efficiënter onderzoek kunnen doen of het onderzoek in publicaties kunnen omzetten. De reputatie en naamsbekendheid van centraal gepositioneerde onderzoekers dragen bijvoorbeeld bij aan snellere publicatie van onderzoek in toonaangevender tijdschriften (Blank, 1991). Kennis, maar ook middelen, concentreren zich vervolgens in onevenredige mate bij personen die centraal staan in een netwerk (Sparrowe et al., 2001; Wasserman en Faust, 1994). Op grond van het voorgaande kan de volgende hypothese worden voorgesteld:

Hypothese 1: Centraal gepositioneerde onderzoekers dragen meer aan innovatie bij dan minder centraal geplaatste onderzoekers.

Gunstenuitruil. De beide aspecten van relaties die een rol spelen bij het Matteüs-effect - structuur en inhoud kunnen samenkomen wanneer 'charisma becomes institutionalized' (Merton, 1968, p.60; cf. Granovetter, 1992). Merton suggereert dat meer centraal gepositioneerde onderzoekers meer giften en andere blijken van erkenning en waardering ontvangen dan onderzoekers aan de randen van een netwerk, ook al is de centrale positie en de erkenning niet altijd terecht (Reagans en McEvily, 2003). 'Kudos' noemt Merton dat ook wel. De economische literatuur over superstars geeft aan waarom de erkenning weleens misplaatst kan zijn (Adler, 1985). In objectieve zin kan de bijdrage die iemand vroeger leverde of nu levert vergelijkbaar zijn aan die van anderen die meer perifeer in het netwerk gelegen zijn. Een toevallig ingezet 'self-confirming process' (Merton, 1968, p. 62) kan ertoe leiden dat de waardering desalniettemin verschilt (vgl. Dolfsma en Leydesdorff, 2009). Desondanks is het van belang het onderscheid tussen deze beide aspecten van structuur en inhoud of aard van relaties te maken.

Naarmate iemand centraler gepositioneerd is als onderzoeker in een laboratorium zal hij, meer dan op grond van kennis of bijdrage gepast is, eerder in staat worden gesteld om een innovatieprojectteam te leiden, zal zijn naam eerder bij een patentaanvraag staan, en zal hij zo een steiler carrièrepad doorlopen (Brass, 1984; Ensign, 2009). Gunsten en giften kunnen veel vormen aannemen. Het kan gaan om erkenning in algemene zin, meer specifieke aanprijzingen, maar ook om citaties van het werk (artikelen of patenten), deelname in een redactieraad, lidmaatschap van een commissie van experts of uitnodiging als keynote spreker. Deelname in een innovatieproject kan een vorm van verlenen van een gunst zijn wanneer de inzet onevenredig klein is in vergelijking met de uitkomst. Deelname in het innovatieproject als gunst aan een ander kan niettemin ook gunstig zijn voor de gever, omdat zonder steun het project wellicht niet gestart zou zijn (Kijkuit en Van den Ende, 2007), niet tot een goed einde zou zijn gekomen of veel minder efficiënt zou zijn geweest.

Naarmate iemand centraler komt te staan, zal hij onevenredig veel meer gunsten krijgen en dat minder dan evenredig reciproceren dan wanneer iemand decentraler staat (Buunk et al., 1993; Bodemann, 1988; Dolfsma et al., 2009; Uzzi, 1997). Iemand die minder centraal staat, zal wellicht objectief bezien iets van minder waarde terugkrijgen maar de reciprociteit toch waarderen (Komter, 1996). Wanneer een gunst op waarde wordt geschat, wegen persoonlijke en omgevingsfactoren mee: een in objectieve zin minder waardevolle gift zal niet tot verstoring van de relatie leiden wanneer de gever over minder middelen of tijd beschikt (Dolfsma et al., 2009).

De social exchange-theorie geeft aan dat een relatie zich voortzet als er over de tijd heen een subjectieve balans van geven en reciproceren is, waarbij een veelheid aan motieven, van macht via eigenbelang naar altruïsme, een rol kan spelen (Dolfsma et al., 2009; Ensign, 2009; Skvoretz en Lovaglia, 1995). Een ander een gunst verlenen kan risicovol zijn, ook al is dat binnen hetzelfde bedrijf. Anderen binnen het bedrijf kunnen de eer opstrijken of andere 
bedrijven kunnen hun voordeel doen met de kennis die wegvloeide (De Laat, 1999; Owen-Smith en Powell, 2004). Hierdoor kan de concurrentiepositie van een bedrijf in gevaar komen. Omdat uitruil van gunsten veelal weloverwogen plaatsvindt, en gebaseerd is op een vorm van calculerend vertrouwen, zal de kans dat de verleende gunst misbruikt wordt klein zijn en kan bovendien op termijn een reciproque gunst verwacht worden. Bij aanvang van een relatie zullen onschuldige gunsten uitgewisseld worden - gunsten die gever en ontvanger niet kunnen schaden - om zo een langetermijnrelatie op te kunnen bouwen waarin gevoeligere en meer kostbare gunsten kunnen worden uitgeruild (Ferrary, 2003; Uzzi, 1997). Gunstenuitruil kan uitmonden in de uitruil van hoogst waardevolle en gevoelige informatie en kennis, in het voordeel van alle betrokken partijen (Bouty, 2000; Dolfsma et al., 2009). Er blijkt dat, in tegenstelling tot wat economen voorspellen, juist nieuwe en waardevolle kennis gedeeld wordt wanneer afdoende 'assurances that rents [return gifts] will follow' aanwezig zijn (Ensign, 2009, p. 106).

Uit studies onder ingenieurs blijkt dat gunstenuitruil een belangrijke rol speelt en innovativiteit bevordert. Wanneer een ingenieur betrokken is in gunstenuitruil, is hij zelf succesvoller en draagt meer bij aan de organisatie (Bouty, 2000; Ensign, 2009). Een belangrijke reden voor meer perifere onderzoekers om de centrale spelers dergelijke eer te bewijzen, is de gedachte dat op enig moment gereciproceerd zal worden (Mauss, 1954, Bouty, 2000).

Naast de structurele kant van relaties in een netwerk, waar Merton veelal op lijkt te doelen en waar anderen ook vooral op wijzen (Lincoln, 1982; Nadler en Tushman, 1988), heeft iemand als Bouty het relationele of de giften(gunsten) uitruilkant van relaties benadrukt. Het laatste wijst op de inhoud van relaties, en duidt op vertrouwen en sociaal kapitaal. De beide aspecten zijn verbonden, maar conceptueel verschillend. Het eerste aspect van relaties is eerder kwantitatief onderzocht, terwijl het tweede veeleer kwalitatief onderzocht is (Bouty, 2000; Heckscher en Adler, 2006) in de antropologische traditie, die nadruk legt op 'thick description' (Geertz, 1973). In deze bijdrage brengen we inzichten uit de verschillende onderzoeksgebieden bijeen in een kwantitatief onderzoek waarin de beide aspecten van relaties geanalyseerd worden. Op grond hiervan stellen we de volgende hypothesen voor:

Hypothese 2: Onderzoekers die meer in daadwerkelijke gunstenuitruil betrokken zijn, worden als innovatiever gezien.

Hypothese 3: Onderzoekers die als genereuzer worden beschouwd, worden als innovatiever gezien.

\section{Data en analyse}

We verzamelden de benodigde data in een R\&Dlaboratorium van een Nederlandse multinational in de chemische industrie met vestigingen in 49 landen (Siggelkow, 2007). Het bedrijf, met een omzet van 8 miljard euro per jaar, is werkzaam in een aantal activiteiten, inclusief voedingsmiddelen en farmaceutische producten, industriële chemicaliën en vezels, en bestaat uit verschillende clusters die ieder relatief autonoom functioneren. Het bedrijf is zich in de loop van de laatste jaren meer gaan richten op specialistische producten die relatief veel waarde toevoegen, waarmee een grotere nadruk op technologie en innovatie gepaard ging; een substantieel deel van de omzet wordt aan R\&D uitgegeven.

Het management steunde het onderzoek actief, en gaf toestemming voor het uitzetten van een elektronische vragenlijst onder 195 onderzoekers en managers in een laboratorium om hun onderlinge netwerkrelaties in kaart te brengen en te kunnen analyseren. Een volledig beeld kan zo ontstaan van wie op welke wijze betrokken is bij kennistransfer en -ontwikkeling; specificatie van de relevante netwerkgrenzen leverde zo geen probleem op (Krackhardt, 1990). Met een responseratio van $97 \%$ voldeden we zeker aan de strenge eisen die gesteld worden aan het verzamelen van netwerkdata (Scott, 1991; Wasserman en Faust, 1994).

Maatstaven. De data zijn verzameld met gebruikmaking van goed in de literatuur gefundeerde schalen om relaties te karakteriseren en een zogenaamde 'name generator'-vraag uit de socialenetwerkliteratuur (Marsden, 1990, 2004). Daarnaast verzamelden we data met betrekking tot de persoon en de positie van de medewerker zoals geslacht, teamgrootte, senioriteit en aanstellingsduur. Figuur 1 geeft een visuele weergave van de kern van het netwerk - alleen dagelijkse en wekelijkse contacten zijn opgenomen. Zes personen bleken volledig geïsoleerd. Van de 1111 relaties blijven 798 contacten over. ${ }^{1}$

Afhankelijke variabelen. Zoals Rodan en Galunic (2004) voorstellen, kan de innovatiebijdrage van een individu gebruikt worden die de directe manager van een respondent, met gebruikmaking van bedrijfsgegevens, geeft. Ideeinnovativiteit tijdens de laatste zes maanden wordt gemeten aan de hand van antwoord op de vraag 'In welke mate is deze persoon creatief, iemand die nieuwe en nuttige ideeën aandraagt, op een schaal van 1-5 van weinig tot uitmuntend?' (cf. Arvey en Murphy, 1998). Zoals gebruikelijk in de literatuur wordt gevraagd naar gedrag tijdens een bepaalde periode, in plaats van naar een houding. Uit tabel 1 in paragraaf 4 blijkt dat deze meer subjectieve innovatiemaatstaf veel variatie liet zien: managers maken wel degelijk onderscheid tussen individuen. 
Figuur 1 Frequent voorkomende relaties in een R\&D-laboratorium

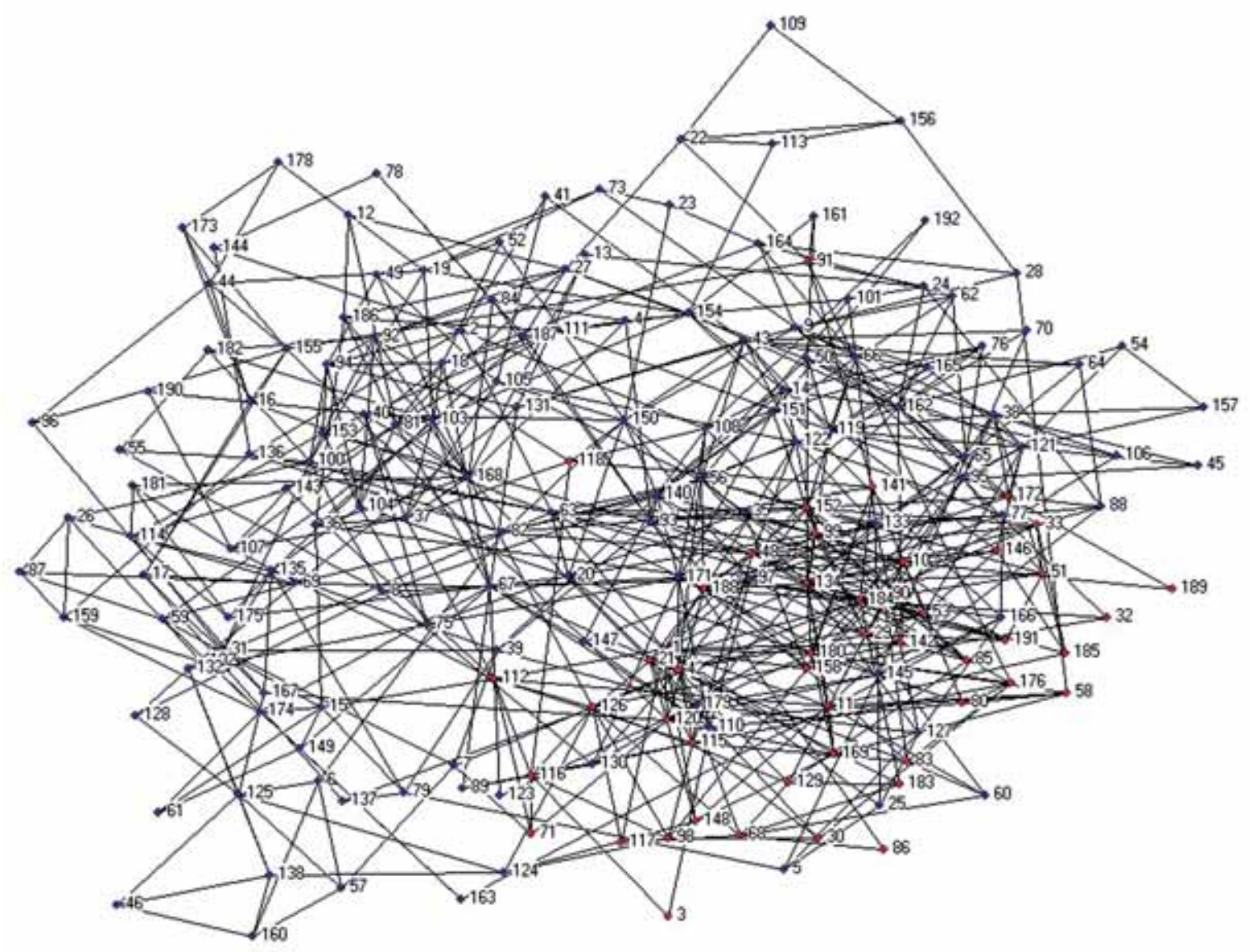

Daarnaast meten we de bijdrage die iemand levert aan de innovativiteit van het laboratorium door het aantal patenten waarbij iemand als aanvrager vermeld staat, te meten. Hoewel het ook geen perfecte, objectieve maatstaf is, is het een veel gebruikte maatstaf op zowel individueel als bedrijfsniveau (Bertin en Wyatt, 1988). Patentinnovativiteit is een objectievere maatstaf dan idee-innovativiteit, omdat voor het eerste sprake is van goed onderbouwde, externe, op wetgeving gebaseerde criteria waaraan voldaan moet worden om met succes een patent aan te vragen. Gebruik van de beide maatstaven als alternatieve onafhankelijke variabelen draagt er toe bij dat een beter inzicht kan ontstaan in de mate waarin de bevindingen robuust zijn. Aangezien het aantal aangevraagde patenten wellicht cumuleert over de tijd heen, moet voor de duur van iemands aanstelling gecontroleerd worden. Opvallend genoeg laat de correlatietabel in de bijlage zien dat de patentmaatstaf voor innovativiteit niet sterk correleert met de meer subjectieve maatstaf van idee-innovativiteit. De resultaten voor patent-innovativiteit en idee-innovativiteit als afhankelijke variabelen, in de modellen in tabel 1, zijn desondanks in grote lijnen vergelijkbaar.
Onafhankelijke variabelen. De contacten voor kennistransfer en -ontwikkeling hebben een structureel of netwerkaspect en een relatie-inhoudelijk aspect (Granovetter, 1992). Om bij dat laatste te beginnen: de mate waarin iemand als genereus gezien wordt, hoeft niet te stroken met de daadwerkelijke mate waarin iemand een ander ongevraagd een dienst bewijst (Buunk et al., 1993). Persoonlijke en situationele omstandigheden spelen hierin een rol. Deze beide relatie-inhoudelijke aspecten van contacten moeten derhalve worden gescheiden. Voor het meten van de frequentie van gunsten verlenen gebruiken we de suggestie van Flynn (2003) om respondenten aan te laten geven hoe vaak met iemand anders een dienst of gunst met betrekking tot het innovatieproces wordt uitgewisseld (gecodeerde schaal naar aantal dagen dat gunsten per jaar werden uitgewisseld; jaarlijks $=1$, per kwartaal $=4$, maandelijks = 12 etc.). Voor iedere respondent werd een gemiddelde berekend. Gepercipieerde generositeit maten we, opnieuw naar Flynn (2003), langs een vijfpunts Likertschaal. We vroegen of iemand naar eigen zeggen in de relatie met anderen die zij noemden meer of minder gunsten deden (van 'ik gaf veel meer dan ik ontving' tot 'ik 
ontving meer dan ik gaf). Bij een hoge waarde voor deze maatstaf, geeft dit aan dat alters ego als genereus zien. Voor iedere respondent is de gemiddelde mate van gepercipieerde generositeit bepaald.

De mate waarin alters aangeven contact met ego te hebben (in-degree centraliteit), geeft een indicatie van de netwerkstructuur voor zover direct relevant voor ego; het geeft aan hoe prominent ego is in de structuur van het netwerk (Scott, 1991; Wasserman en Faust, 1994). Omdat deze maatstaf niet afhankelijk is van rapportage door ego zelf, is deze betrouwbaarder (Sparrowe et al., 2001). Een ieder werd gevraagd om werkgerelateerde contacten (geen, tot maximaal veertien) te noemen aan wie in de laatste zes maanden regelmatig (onderzoeksgerelateerde) informatie en advies werd gevraagd om de eigen effectiviteit als onderzoeker te verhogen (zogenaamde waardevolle werkcontacten). Voor iedereen in het netwerk kon zo de in-degree centraliteit berekend worden. Omdat sommige contacten asymmetrisch zullen zijn, bleek niet iedere relatie reciproque vooral belangrijkere mensen hoger in de hiërarchie zullen minder snel reciproceren (Knoke en Burt, 1983), al was het maar omdat zij vermoedelijk meer contacten hebben dan zij actief onderhouden of noemen.

Controlevariabelen. Het geslacht van een respondent ( $23 \%$ vrouw) en de duur van iemands anstelling in jaren (gemiddeld: 14,6; standaarddeviatie: 11,32, minimum: 1, maximum: 43) zijn twee controlevariabelen. Door de duur van de aanstelling te nemen, in plaats van iemands leeftijd, controleren we voor de bedrijfsspecifieke kennis die iemand heeft opgedaan. Opnemen van de leeftijd (gemiddeld: 44; standaarddeviatie: 9) in plaats van duur van aanstelling bleek overigens statistisch geen verschil te maken in de regressieanalyses, maar is om inhoudelijke redenen niet verkozen. In de twaalf departementen, maar ook op het niveau van de twee overkoepelende businessunits kunnen leereffecten als gevolg van specialisatie een gunstig effect hebben op innovativiteit. In navolging van Tortoriello (2006) nemen we het mogelijke effect van schaaleffecten op het niveau van het departement mee in onze analyse. Departementsgrootte, van de relatiefkleinere groepen binnen een businessunit, kan aangeven of frequent interacteren op vergelijkbare, specialistische onderwerpen tussen onderzoekers gunstig is voor innovativiteit. Data over de hiërarchische positie die een respondent inneemt (senioriteit) werden verstrekt vanuit $\mathrm{P} \& \mathrm{O}$. We maken onderscheid tussen scientist, senior scientist en science manager.

In de bijlage worden beschrijvende statistieken gepresenteerd. Duidelijk is dat een meer complexe, en minder eenduidig te interpreteren statistische methodiek dan ordinary least squares (OLS) niet aan de orde is. De resultaten van de regressieanalyses in tabel 1 geven aan dat multicollineariteit geen rol speelt.

\section{Resultaten}

Als element dat de relatie karakteriseert, voegden we allereerst de daadwerkelijke frequentie van gunstenuitruil toe, om daarna in-degree centraliteit toe te voegen als indicatie van de structuur van het netwerk van relaties, en uiteindelijk ook de gepercipieerde generositeit. De laatste geeft een indicatie van de mate waarin iemand zeer waarschijnlijk in de nabije toekomst bij kennis- en innovatiegerelateerde gunstenuitruil betrokken zal zijn (Bouty, 2000; Ensign, 2009). Elke modelspecificatie wordt voor zowel idee- als patent-innovativiteit geanalyseerd. De resultaten van de hiërarchische regressieanalyses, zoals getoond in tabel 1 , laten zien in welke mate de structuur of de inhoud van de relaties bepalend is voor de innovativiteit van onderzoeker in een R\&D-laboratorium. ${ }^{2}$

De frequentie van gunstenuitruil heeft opvallend genoeg alleen een significant effect op idee-innovativiteit. De significantie is niet groot, en het effect verdwijnt in de modellen drie en vijf, maar het effect is in tegenstelling tot onze verwachting negatief. Wanneer iemand daadwerkelijk meer betrokken is in gunstenuitruil, wordt hij als minder innovatief bestempeld. Wanneer als variabele centraliteit wordt toegevoegd, dan blijkt dat het effect op innovativiteit positief is, zoals verwacht, maar opvallend genoeg minder significant voor de patent-innovativiteit. Gepercipieerde generositeit levert als variabele geen bijdrage aan de verklaring voor wat onderzoekers in een laboratorium innovatief maakt. Introductie van deze laatste variabele zorgt er tevens voor dat frequentie van gunstenuitruil als verklarende variabele die een significante bijdrage levert, verdwijnt.

Hoewel de verschillende aspecten in de bijdrage van Merton zelf gezamenlijk gepresenteerd worden, blijken hun effecten niet alleen conceptueel maar ook statistisch verschillend te zijn. Van de aspecten aan de relaties waar kennis wordt uitgewisseld en ontwikkeld, zoals Merton suggereert, blijft alleen het structurele aspect over. De structuur van een netwerk beïnvloedt de interacties die ego met alters zal hebben. De mate waarin een actor een centrale positie in het netwerk inneemt, vergroot het aantal mogelijkheden om kennis uit te wisselen (Lawler et al., 2000; Skvoretz en Lovaglia, 1995). Ego staan meer (onderzoeks)ideeën, maar ook middelen in de bredere zin van het woord, ter beschikking (cf. Kijkuit en van den Ende, 2007). Meer contacten gaat veelal samen met meer diverse contacten; op een snijvlak staan waar verschillende vormen van kennis samenkomen, ontstaat ook veelal nieuwe kennis (Burt, 2004). Onze conclusie is derhalve dat hypo- 
Tabel 1 Innovativiteit van onderzoekers in een R\&D-laboratorium

\begin{tabular}{|c|c|c|c|c|c|c|}
\hline & Idee-perf. & Patent-perf. & Idee-perf. & Patent-perf. & Idee-perf. & Patent-perf. \\
\hline Variabele & 1 & 2 & 3 & 4 & 5 & 6 \\
\hline Duur aanstelling & $-0,228^{\star *}$ & $0,143+$ & $-0,229^{* *}$ & $0,143+$ & $-0,235^{\star \star}$ & $0,137 \dagger$ \\
\hline Geslacht & $-0,2^{\star \star}$ & $-0,132 \dagger$ & $-0,183^{\star *}$ & $-0,116$ & $-0,186^{\star \star}$ & $-0,119$ \\
\hline Dept. grootte & $-0,07$ & 0,079 & $-0,07$ & 0,078 & $-0,063$ & 0,086 \\
\hline Businessunit & $0,395^{\star \star}$ & $-0,016$ & $0,411^{\text {**}}$ & 0,002 & $0,416^{* *}$ & 0,007 \\
\hline Departement & $-0,368^{\star \star}$ & 0,024 & $-0,451^{\star *}$ & $-0,057$ & $-0,454^{* *}$ & $-0,061$ \\
\hline Senioriteit: sr. scientist & $0,188^{\star \star}$ & $0,23^{\star \star}$ & $0,142 \dagger$ & $0,19^{*}$ & $0,141 \dagger$ & $0,189^{*}$ \\
\hline Senioriteit: management & $0,184^{*}$ & $0,215^{*}$ & 0,099 & 0,14 & 0,101 & 0,141 \\
\hline Exchange freq. & $-0,138^{*}$ & 0,081 & $-0,115 \dagger$ & 0,101 & $-0,107$ & 0,109 \\
\hline In-degree centraliteit & & $0,212^{\star *}$ & $0,191^{*}$ & $0,213^{\star *}$ & $0,191^{*}$ & \\
\hline Gepercipieerde generositeit & & & & $-0,039$ & $-0,04$ & \\
\hline $\mathrm{R}^{2}$ & 0,233 & 0,123 & 0,265 & 0,149 & 0,266 & 0,15 \\
\hline Adj. $R^{2}$ & 0,197 & 0,083 & 0,226 & 0,104 & 0,223 & 0,101 \\
\hline Overall F & 6,597 & 3,063 & 6,915 & 3,372 & 6,231 & 3,052 \\
\hline$d f$ & 182 & 183 & 182 & 183 & 182 & 183 \\
\hline
\end{tabular}

thesen 2 en 3 beide verworpen moeten worden, terwijl hypothese 1 bevestigd is.

Resultaten voor de opgenomen controlevariabelen laten additioneel licht schijnen op de vraag hoe relaties bijdragen aan innovativiteit. Het R\&D-laboratorium wordt gedomineerd door mannen. Vrouwen worden gezien als minder innovatief, vooral wat betreft idee-innovativiteit. Wanneer andere aspecten van onderzoeksrelaties toegevoegd worden, blijkt dit effect voor patent-innovativiteit statistisch echter niet langer significant. Wellicht wordt de bijdrage van vrouwen ondergewaardeerd of kunnen zij minder steunen op de nodige contacten. Medewerkers die langer in dienst zijn, worden ook als minder idee-innovatief gezien, terwijl ze juist (iets) meer patent-innovatief blijken te zijn. Figuur 2 visualiseert gestileerde voorbeelden van de egonetwerken van een scientist, senior scientist en science manager. ${ }^{3}$ In figuur 1 zijn deze egonetwerken middenboven terug te vinden. Netwerken van een senior scientist (103) en een science manager (152) zijn duidelijk groter, maar blijken ook meer divers dan dat van een scientist (node 113). Deze observaties zijn ook voor managers relevant.

Senior scientists zijn zowel wat betreft het genereren van ideeën als wat betreft het aanvragen van patenten innovatief, zelfs na controle voor centraliteit, en leveren een duidelijk inhoudelijke bijdrage. Een science manager is innovatief, maar zodra in de analyse centraliteit opge- nomen wordt, valt dat effect weg. Science management moet het klaarblijkelijk vooral van zijn positie in het netwerk hebben. Voordelen van specialisatie en schaal zijn opvallend genoeg niet terug te vinden op het lagere niveau van het departement, maar wel op dat van de in omvang grotere businessunit. Samenbrengen van een relatief beperkt aantal experts op een specifiek kennisterrein heeft geen effect op innovativiteit. Dat dit de idee-innovativiteit zelfs negatief kan beïnvloeden, is bovendien opvallend. ${ }^{4}$

\section{Conclusies}

Netwerkanalyse van patronen van kennisdeling binnen een organisatie laat een aantal opvallende en - voor het management - bemoedigende resultaten zien. Het netwerk van relaties blijkt een belangrijke rol te spelen bij het verklaren van de innovativiteit van medewerkers in een laboratorium (Aalbers et al., 2009; Allen en Cohen, 1969; Sparrowe, 2001). Op grond van ontwikkelingen in de literatuur is aan te geven dat er (ten minste) twee aspecten aan relaties te onderkennen zijn: de structurele en de inhoudelijke. Uit ons onderzoek blijkt dat de structurele kant van relaties beduidend belangrijker is dan de inhoudelijke: centraal gepositioneerd zijn in een netwerk waar kennis uitgewisseld wordt, draagt significant bij aan de idee- en patent-innovativiteit van een medewerker. Daadwerkelijk veel betrokken zijn in gunstenuitruil, of meer algemeen als genereus gepercipieerd te worden, bleek nauwelijks effect te hebben. 
Figuur 2 Egonetwerken

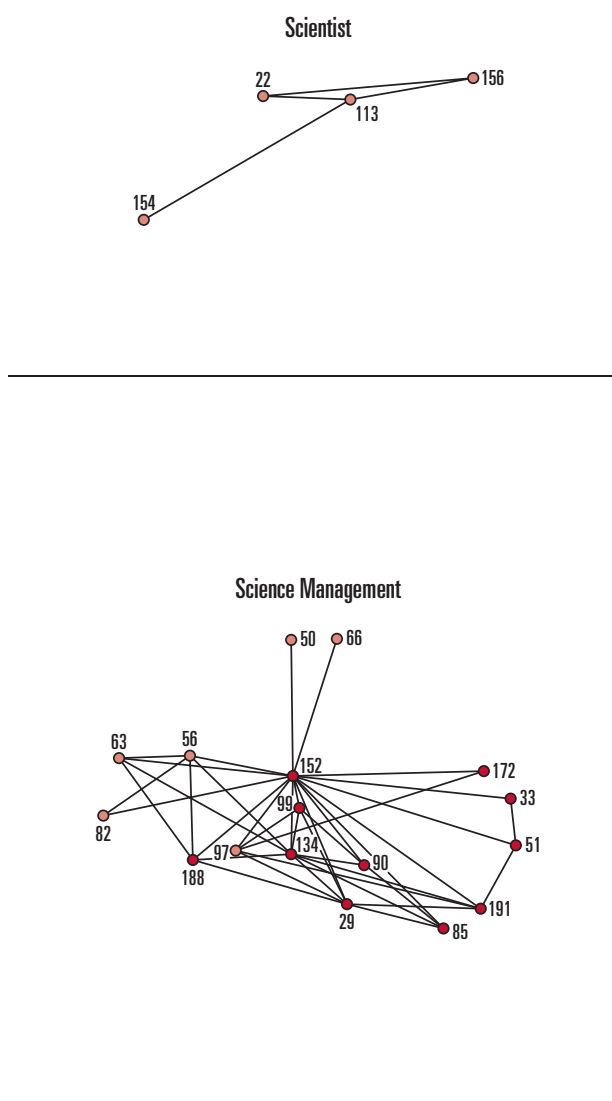

Er zijn duidelijke beperkingen te onderkennen aan het onderzoek dat we hier presenteren. Onze studie betreft één enkel bedrijf. Dat is onvermijdelijk bij dit type onderzoek, omdat het verzamelen van de benodigde data extreem arbeidsintensief is en daarnaast toegang tot bedrijven moeilijker is dan voor menig ander type onderzoek. Data verzameld voor één bedrijf kunnen bovendien niet toegevoegd worden aan data voor andere bedrijven. De gebruikte statistische methodiek (OLS) is een andere beperking. De aard van de data vraagt niet nadrukkelijk om een andersoortige analyse dan de direct interpreteerbare OLS-techniek. Toekomstig onderzoek moet uitwijzen in welke mate de inzichten in dit artikel gerepliceerd worden. Belangrijke deelbevindingen, met name in relatie tot de structuur van relaties (centraliteit), zijn uit de literatuur bekend. De combinatie van theoretische perspectieven in een kwantitatief onderzoek levert zo belangrijke inzichten op.

Wanneer een organisatie het relevante netwerk in kaart heeft, kan het management van een organisatie duidelijk lering trekken en gericht tot herontwerp komen. Zo kunnen lacunes afgedicht worden, redundanties inzichtelijk worden en mogelijke disrupties in de toekomst
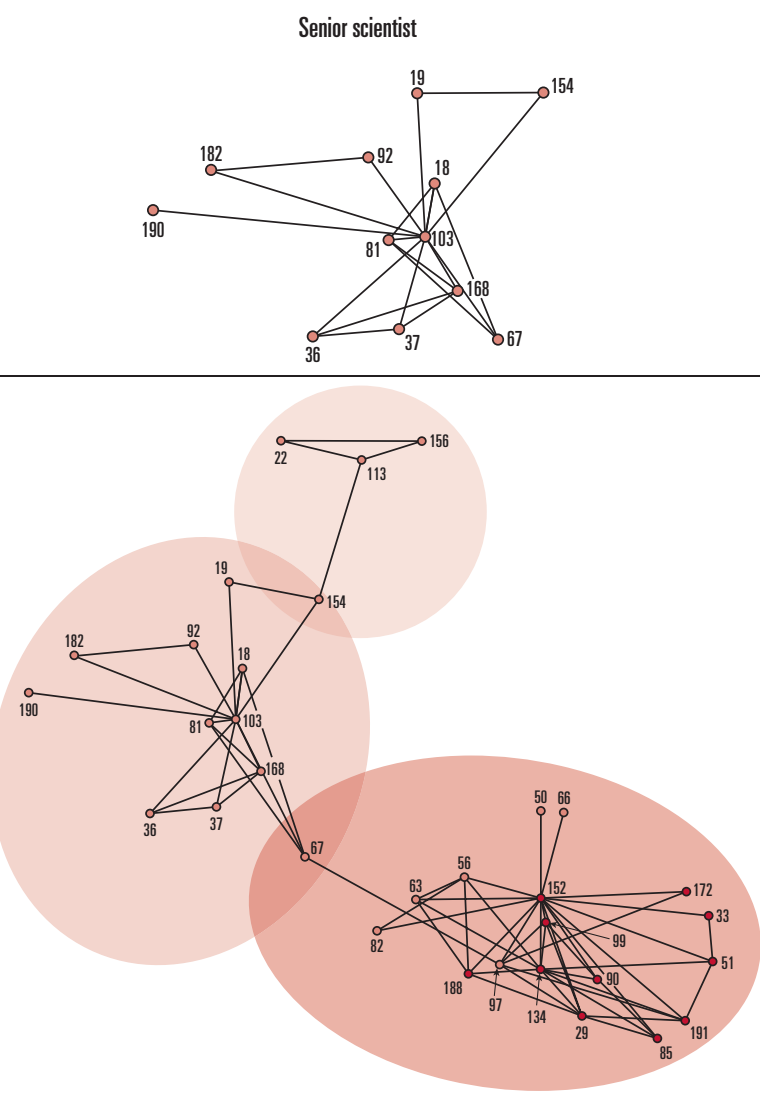

eenvoudiger opgevangen worden. Wanneer bijvoorbeeld de informatiestroom tussen onderzoeksgroepen afhankelijk blijkt te zijn van een of twee mensen, betekent het wegvallen van deze individuen een mogelijk sterk verminderde kennisuitwisseling. De structuur van een netwerk, zoals zichtbaar in het aantal contacten dat mensen hebben, kan relatief eenvoudiger door het management beïnvloed worden dan de inhoud van de relaties. Met de bijdrage in dit artikel is daarmee meer begrip van het proces van kenniscreatie aangedragen, hetgeen tot een betere sturing ervan kan leiden.

Dr. Rene (R.A.) van der Eijk is onderzoeker aan RSM Erasmus University en aan de University of Groningen School of

Economics and Business. Zijn onderzoek richt zich op de rol van netwerken bij kennisuitwisseling en innovatie.

Prof. dr. drs. Wilfred (W.A.) Dolfsma is hoogleraar innovatie aan de University of Groningen School of Economics and Business. Hij is directeur van het SOM onderzoeksinstituut Innovation \& Organization. Zijn onderzoek richt zich onder meer op samenwerking ten behoeve van innovatie tussen en binnen organisaties. 
I. Multidimensionale schalingstechnieken plaatsen nodes die 'vergelijkbaar' zijn, omdat ze elkaar of dezelfde derden noemen, bij elkaar. 2 Alle correlaties zijn lineair: we vonden geen curvi-lineaire effecten voor gepercipieerde generositeit, in-degree centraliteit, of frequentie van gunstenuitruil.

3 Een egonetwerk is een focal node ('ego') en nodes waarmee ego direct relateert ('alters'), plus de mogelijke relaties van die alters onderling.
4 De neiging tot patenteren ('propensity to patent') verschilt niet tussen de businessunits; in het relevante kennisdomein is de gemiddelde neiging tot patenteren hoog (Arundel en Kabla, 1998).

\section{Literatuur}

Aalbers, R., W. Dolfsma en O. Koppius (2009), Intraorganizational knowledge transfer and multiplexity: the strength of rich ties, mimeo, University of Groningen.

- Adler, M. (1985), Stardom and talent, American Economic Review, vol. 75, no. 1, pp. 208-212.

allen, T.J. en S.I. Cohen (1969), Information flow in research and development laboratories, Administrative Science Quarterly, vol. 14, pp. 12-19.

- Ancona, D. en D. Caldwell (1987), Management issues facing new product teams in high technology companies, in: D. Lewin, D. Lipsky en D. Sokel (redactie), Advances in industrial and labor relations, no. 4, Greenwich, CT, JAI Press, pp. 191-221.

- Arundel, A. en I. Kabla (1998), What percentage of innovations are patented? Empirical estimates for European firms, Research Policy, vol. 27, pp. 127-41.

- Arvey, R.D. en K.R. Murphy (1998), Performance evaluation in work settings, Annual Review of Psychology, vol. 49, pp. 141-168. - Autio, E., A. Hameri en O. Vuola (2004), A framework of industrial knowledge spillovers in big-science centers, Research Policy, vol. 33, pp. 107-126.

Belsley, D.A., E. Kuh en R.E. Welsch (1980), Regression diagnostics: identifying influential data and sources of collinearity, New York: John Wiley.

- Bertin, G.Y. en S. Wyatt (1988),

Multinationals and industrial property, New York: Harvester Wheatsheaf

Blank, R.M. (1991), The effects of double-blind versus single-blind reviewing: experimental evidence from the American Economic Review, American Economic Review, vol. 81, no. 5, pp. 1041-1067.

- Bodemann, Y.M. (1988), Relations of production and class rule: the hidden basis of patron-clientage, in: B. Wellmann en S.D. Berkowitz (redactie), Social structures: a network approach, Cambridge: Cambridge UP. - Bouty, I. (2000), Interpersonal and interaction influences on informal resource exchanges between R\&D researchers across organizational boundaries, Academy of Management Journal, vol. 43, no. 1, pp. 50-65. Brass, D. (1984), Being in the right place: a structural analysis of individual influence in an organization, Administrative Science Quarterly, vol. 29, pp. 518-539.

Burt, R.S. (2004), Structural holes and good ideas, American Journal of Sociology, vol. 110 , no. 2, pp. 349-399.

- Burt, R.S. (1992), Structural holes: The social structure of competition, Cambridge, MA: Harvard UP.

Buunk, B.P., B.J. Doosje, L.G.J.M. Jans en L.E.M. Hopstaken (1993), Perceived reciprocity, social support, and stress at work: the role of exchange and communal orientation, Journal of Personality and Social Psychology vol. 65, no. 4, pp. 801-811.

- Cross, R. en J.N. Cummings (2004), Tie and network correlations of individual performance in knowledge-intensive work, Academy of Management Journal, vol. 47, no. 6, pp. 928937.

Danneels, E. (2002), The dynamics of product innovation and firm competences, Strategic Management Journal, vol. 23, pp. 1051121.

- Dolfsma, W., R. van der Eijk en A. Jolink (2009), On a source of social capital: gift exchange, Journal of Business Ethics, vol. 89, no. 3, pp. 315-329.

- Dolfsma, W. en L. Leydesdorff (2009), Lockin \& break-out from technological trajectories: modeling and policy implications, Technological Forecasting and Social Change, vol. 76, no. 7, 932-941.
Ensign, P.C. (2009), Knowledge sharing among scientists, New York: Palgrave Macmillan.

-Ferrary, M. (2003), The gift exchange in the social networks of Silicon Valley, California Management Review, vol. 45, no. 4, pp. 120 138

Elynn, F.J. (2003), How much should I give and how often? The effects of generosity and frequency of favor exchange on social status and productivity, Academy of Management Review, vol. 46, no. 5, pp. 539-553.

- Geertz, C. (1973), The interpretation of cultures: selected essays, New York: Basic Books.

- Goffman, E. (1971), Relations in public, Harmondsworth: Penguin.

- Granovetter, M.S. (1992), Problems of explanations in economic sociology, in: N. Nohria en R. Eccles (eds.), Networks and organizations: structure, form and action, Boston: Harvard Business School.

- Heckscher, C. en P.S. Adler (2006), The firm as a collaborative community - reconstructing trust in the knowledge economy, New York: Oxford UP.

- Ibarra, H. (1993), Network centrality, power and innovation involvement: determinants of technical and administrative roles, Academy of Management Journal, vol. 36, no. 3, pp. 471-501. - Kijkuit, B. en J. van den Ende (2007), The organizational life of an idea: integrating social network, creativity and decision-making perspectives, Journal of Management Studies, vol. 44, no.6, pp. 863-882.

- Knoke, D. en R.S. Burt (1983), Prominence, in: R.S. Burt en M.J. Minor (redactie), Applied network analysis, Beverly Hills, CA; Sage, pp. 195-222.

- Komter, A.E. (1996), The gift: an interdisciplinary approach, Amsterdam: Amsterdam UP. 
Krackhardt, D. (1990), Assessing the political landscape: structure, cognition, and power in organizations, Administrative Science Quarterly, vol. 35, pp. 342-369

- Laat, P.B. de (1999), Dangerous liaisons: sharing knowledge within $R \& D$ alliances, in: $A$. Grandori (redactie), Interfirm networks, organizations and industrial competitiveness, London: Routledge.

- Lam, A. (2005), Work roles and careers of R\&D scientists in network organizations, Industrial Relations, vol. 44, no. 2, 242-275. - Lawler, E., S. Thye en J. Yoon (2000), Emotion and group cohesion in productive exchange, American Journal of Sociology, vol. 106, pp. 616-657.

- Lincoln, J. (1982), Intra- (and Inter-) organizational networks, in: S. Bacharach (redactie), Research in the sociology of organizations, vol. 1, Greenwich, CT: JAI press, pp.1-38.

- March, J.G. en H.A. Simon (1958), Organizations, New York: Wiley.

- Marsden, P.V. (1990), Network data and measurement, Annual Review of Sociology, vol. 16, pp. 453-63.

- Marsden, P.V. (2004), Recent developments in network measurement, in: P.J. Carrington, J.
Scott en S. Wasserman (eds.), Models and methods in social network analysis, New York: Cambridge UP.

Mauss, M. (1954) [2000], The gift. New York: Norton.

- Mehra, A., M. Kilduff en D. Brass (2001), The social networks of high and low-self monitors: implications for workplace performance, Administrative Science Quarterly, vol. 46, pp. 121-146.

Merton, R.K. (1968), The matthew effect in Science, Science, vol. 159, pp. 56-63.

- Nadler, D. en M. Tushman (1988), Strategic Organization Design, Glenview, III: Scott Foresman.

口 Owen-Smith, J. en W.W. Powell (2004), Knowledge networks as channels and conduits, Organization Science, vol. 15, no. 1, pp. 5-21.

- Reagans, R. en R. McEvily (2003), Network structure and knowledge transfer: the effect of cohesion and range, Administrative Science Quarterly, vol. 48, pp. 240-267.

- Rodan, S. en C. Galunic (2004), More than network structure: how knowledge heterogeneity influences managerial performance and innovativeness, Strategic Management Journal, vol. 25, pp. 541-562.
Scott, J. (1991), Social network analyses, London: Sage.

- Siggelkow, N. (2007), Persuasion with case studies, Academy of Management Journal, vol. 50, no. 1, pp. 20-24.

- Skvoretz, J. en M.J. Lovaglia (1995), Who exchanges with whom, Social Psychology Quarterly, vol. 58, pp. 163-177.

- Sparrowe, R.T., R.C. Liden, S.J. Wayne en M.L. Kraimer (2001), Social networks and the performance of individuals and groups, Academy of Management Journal, vol. 44, no. 2, pp. 316-325.

- Tortotiello, M. (2006), The social underpinnings of absorptive capacity: external knowledge, social networks, and individual innovativeness, Academy of Management Best Paper Proceedings.

- Uzzi, B. (1997), Social structure and competition in interfirm networks: the paradox of embeddedness, Administrative Science Quarterly, vol. 42, no. 1, pp. 35-67.

-Wasserman, S. en K. Faust (1994), Social network analysis: methods and applications, New York: Cambridge UP.

-Wuchty, S., B. Jones en B. Uzzi (2007), The increasing dominance of teams in the production of knowledge, Science, vol. 316, May, pp. 1036-9.

\section{Bijlage 1 Beschrijvende statistieken}

\begin{tabular}{|c|c|c|c|c|c|c|c|c|c|c|c|c|}
\hline Variabele & Gemiddelde & S.d. & 1 & 2 & 3 & 4 & 5 & 6 & 7 & 8 & 9 & 10 \\
\hline 1. Tenure & 15,5794 & 11,37251 & 1 & & & & & & & & & \\
\hline 2. Gender & 0,2256 & 0,41908 & $-0,293^{* *}$ & 1 & & & & & & & & \\
\hline 3. Dept. Grootte & 12,8564 & 5,13427 & $-0,133$ & 0,08 & 1 & & & & & & & \\
\hline 4. Business unit & 0,2564 & 0,43777 & 0,056 & $-0,064$ & $-0,332^{* *}$ & 1 & & & & & & \\
\hline 5. Dept. & 9,5179 & 5,81355 & 0,073 & $-0,116$ & $-0,396^{* *}$ & $0,818^{\star \star}$ & 1 & & & & & \\
\hline 6. Sr. scientist & 0,1538 & 0,36173 & $-0,021$ & $-0,162^{*}$ & 0,062 & $-0,023$ & 0,097 & 1 & & & & \\
\hline 7. Sc. management & 0,3231 & 0,46886 & 0,066 & $-0,006$ & $-0,437^{\star *}$ & $-0,104$ & $-0,132$ & $-0,295^{* *}$ & 1 & & & \\
\hline 8. Uitruil freq. & 40,3456 & 38,76958 & $-0,08$ & 0,016 & 0,08 & $-0,106$ & $-0,044$ & 0,051 & $-0,193^{\star \star}$ & 1 & & \\
\hline 9. In-degree centraliteit & 9,8289 & 7,55785 & 0,08 & $-0,147^{*}$ & $-0,270^{\star *}$ & $0,310^{\star *}$ & $0,231^{\star *}$ & 0,088 & $0,324^{* \star}$ & $-0,211^{* *}$ & 1 & \\
\hline $\begin{array}{l}\text { 10. Gepercipieerde } \\
\text { generositeit }\end{array}$ & 3,0484 & 0,34913 & $-0,159^{*}$ & $-0,009$ & $0,193^{* *}$ & $-0,086$ & $-0,043$ & 0,029 & $-0,097$ & $0,222^{* *}$ & $-0,073$ & 1 \\
\hline 11. Idee-Innov. & 1,8519 & 2,00777 & $0,155^{*}$ & $-0,214^{\star *}$ & $-0,036$ & $-0,019$ & 0 & $0,200^{* *}$ & 0,114 & 0,042 & $0,220^{* *}$ & $-0,041$ \\
\hline 12. Patent-Innov. & 3,4433 & 0,93818 & $-0,126$ & $-0,217^{\star *}$ & $-0,148^{*}$ & $-0,022$ & $0,143^{*}$ & $0,178^{*}$ & 0,13 & $-0,134$ & $0,267^{\star *}$ & $-0,036$ \\
\hline
\end{tabular}

